\title{
KOHESI DAN KOHERENSI DALAM RUBRIK OLAHRAGA HARIAN RAKYAT BENGKULU
}

\author{
Reci Apreno, Suryadi, dan Bambang Djunaidi \\ Program Studi Pendidikan Bahasa Indonesia \\ Jurusan Pendidikan Bahasa dan Seni \\ FKIP Universitas Bengkulu \\ reciapreno@gmail.com
}

\begin{abstract}
Abstrak
Tujuan penelitian untuk mengetahui dan mendeskripsikan penggunaan peranti kohesi dan koherensi pada rubrik ALL SPORT Harian Rakyat Bengkulu. Penelitian ini menggunakan metode deskriptif kualitatif. Data dalam penelitian ini berupa teks wacana berita yang bersumber dari rubrik ALL SPORT Harian Rakyat Bengkulu edisi Maret 2018. Teknik pengumpulan data menggunakan teknik dokumentasi. Teknik analisis dilakukan dengan analisis wacana. Dalam penelitian ini keabsahan data dilakukan dengan triangulasi. Hasil penelitian ini ditemukan penggunaan peranti kohesi dan koherensi pada teks wacana berita rubrik ALL SPORT Harian Rakyat Bengkulu edisi 2018 yaitu, kohesi gramatikal meliputi pronomina, substitusi, konjungsi, dan kohesi leksikal berupa repetisi atau pengulangan. Kekoherensian pada wacana berita rubrik ALL SPORT Harian Rakyat Bengkulu edisi Maret 2018 ditunjukkan dengan penggunaan peranti kohesi gramatikal seperti pronomina, substitusi, konjungsi, dan leksikal berupa kohesi repetisi. Selain itu kekoherensian wacana juga ditunjukkan dari topik atau informasi yang terkandung di setiap bagian wacana dengan cara melihat apakah di setiap bagian wacana menjelaskan satu topik dan menyampaikan informasi yang sesuai dengan judul wacana. Berdasarkan hasil penelitian maka disimpulkan bahwa kohesi gramatikal dan kohesi leksikal memiliki peran masing-masing dalam pembentukan wacana, sehingga wacana berita rubrik ALL SPORT Harian Rakyat Bengkulu menjadi koheren.
\end{abstract}

Kata kunci : kohesi, koherensi, rubrik Olahraga Harian Rakyat Bengkulu

\begin{abstract}
The aim of the study was to find out and describe the use of cohesion and coherence devices in the Bengkulu SPORT Daily People rubric rubric. This study used descriptive qualitative method. The data in this study are in the form of news discourse texts originating from the March 2018 edition of the ALL SPORT of the People's Daily Bengkulu. Data collection techniques use documentation techniques. The analysis technique is done by discourse analysis. In this study the validity of the data is done by triangulation. The results of this study found the use of cohesion and coherence tools in the discourse text of the ALL SPORT Daily Bengkulu rubric edition 2018, namely, grammatical cohesion including pronouns, substitutions, conjunctions, and lexical cohesions in the form of repetition or repetition. The coherence in the March 2018 edition of the ALL SPORT Daily People's Daily News rubric is shown by the use of grammatical cohesion tools such as pronouns, substitutions, conjunctions, and lexicals
\end{abstract}


in the form of cohesion repetitions. Besides the discourse coherence is also shown from the topic or information contained in each part of the discourse by looking at whether in each part of the discourse explains one topic and conveys information that is in accordance with the title of the discourse. Based on the results of the study, it was concluded that grammatical cohesion and lexical cohesion had their respective roles in the formation of discourse, so that the news discourse in the rubric of the ALL SPORT Bengkulu People's Daily became coherent.

\section{Keywords: cohesion, coherence, Bengkulu People's Daily Sports rubric.}

\section{PENDAHULUAN}

Wacana merupakan satuan bahasa yang terlengkap dan tertinggi atau terbesar di atas kalimat atau klausa dengan kohesi dan koherensi tinggi, berkesinambungan satu dengan yang lainnya dan memiliki awal dan akhir yang nyata, disampaikan secara lisan maupun tulisan (Tarigan, 2009:26). Sebagai satuan bahasa yang tertinggi dalam kebahasaan, wacana bukanlah susunan kalimat secara acak, melainkan tersusun dengan keterpaduan (kohesi) dan memiliki kerapian (koherensi).

Wacana dapat dibagi menjadi dua yaitu wacana lisan dan wacana tulis wacana lisan adalah wacana yang disampaikan melalui lisan atau langsung yang memiliki unsur latar dan pengiring non kebahasaan (Sukino,2004:38). Kegunaan kedua unsur tersebut dapat lebih memudahkan seorang untuk memahami wacana. Sedangkan wacana tulis merupakan wacana yang dihasilkan melalui media tulisan, dalam perwujudannya wacana tulis miskin akan unsur latar dan pengiring. Karena itu wacana tulis menuntut unsur-unsur wacana yang lebih panjang daripada wacana lisan, kelengkapan struktur kebahasaan menjadi penting sebagai sarana pengungkapan makna dalam tulisan (Sukino, 2004:44). Contoh wacana tulis bisa kita temukan dengan mudah dalam kehidupan seharihari seperti, dalam majalah, buku, surat kabar, dan sebagainya.
Surat kabar adalah lembaran tercetak yang memuat laporan yang terjadi di masyarakat dengan ciri-ciri terbit secara periodik, bersifat umum, isinya termasa dan teraktual mengenai apa saja dan dimana saja di seluruh dunia untuk diketahui pembaca. Surat kabar dalam merepresentasikan realitas termasuk ideologi tentu menggunakan bahasa, sehingga realitas yang sebenarnya menjadi terdistorsi. Pada konteks tersebut, surat kabar bukan saja menjadi titik perhatian dari ilmu komunikasi melainkan juga dapat menjadi kajian bahasa (Badara, 2012:2). Di Indonesia terdapat banyak jenis surat kabar yang terdiri dari surat kabar nasional dan lokal. Surat kabar nasional memiliki jangkauan yang lebih luas seperti surat kabar Harian Kompas, surat kabar Tempo, surat kabar Media Indonesia, dan sebagainya. Sedangkan surat kabar lokal jangkauannya lebih sempit seperti yang terdapat di Bengkulu jangkauannya hanya di daerah Bengkulu, contoh Radar Bengkulu, Bengkulu Ekspres, Harian Rakyat Bengkulu dan sebagainya.

Harian Rakyat Bengkulu merupakan salah satu surat kabar terbesar dan memiliki jangkauan terluas di Provinsi Bengkulu yang telah berdiri kurang lebih 16 tahun, surat kabar Harian Rakyat Bengkulu terbit setiap hari dengan 24-32 halaman serta mengandung informasi yang beragam seperti berita ekonomi, politik, kriminal, olahraga dan sebagainya. Sebagai salah 
satu surat kabar terbesar di Provinsi Bengkulu sudah pasti banyak warga Bengkulu yang berlangganan surat kabar Harian Rakyat Bengkulu, sehingga Harian Rakyat Bengkulu menjadi salah satu koran yang paling populer di masyarakat Bengkulu. Dalam Harian Rakyat Bengkulu, berita sudah dikelompokkan berdasarkan tema tertentu seperti politik, ekonomi, kriminal, kesehatan, zitizen, olahraga, dan sebagainya. Hal itu dilakukan untuk memudahkan pembaca menemukan informasi yang dicari, pengelompokan tersebut dinamakan rubrik.

Rubrik adalah karangan yang bertema tertentu dalam surat kabar, majalah, dan sebagainya (KBBI). Seperti Dalam Harian Rakyat Bengkulu terdapat rubrik olahraga berjudul, ALL SPORT yang terbit setiap hari dan memuat berbagai informasi mengenai olahraga. Rubrik ALL SPORT memiliki konten yang beragam, konten pertama berisi tentang berita yang sedang banyak dibicarakan mengenai olahraga, kedua berisi tentang tokoh olahraga seperti atlet sepak bola maupun atlet olahraga lain, dan yang terakhir mengulas tentang berita di daerah yang berkaitan dengan olahraga. Informasi mengenai olahraga saat ini semakin digemari, hal tersebut bisa dilihat pada setiap media cetak maupun media elektronik pasti menyediakan informasi tentang olahraga. Oleh karena itu dapat dikatakan bahwa informasi mengenai olahraga merupakan salah satu kebutuhan bagi masyarakat.

Setiap wacana pasti memiliki peranti kohesi dan koherensi, seperti yang dikemukakan oleh Kridalaksana (1983:179) wacana (discourse) merupakan satuan bahasa terlengkap, dalam tataran kebahasaan merupakan satuan gramatikal tertinggi atau terbesar yang memiliki kepaduan (kohesi) dan kerapian (koherensi). Begitu juga dengan wacana berita yang terdapat pada rubrik ALL SPORT Harian Rakyat Bengkulu yang memiliki peranti kohesi dan koherensi, hal itu dibuktikan pada saat penulis melakukan pengamatan awal dan penulis menemukan penggunaan peranti kohesi yang digunakan pada rubrik ALL SPORT cukup bervariasi, seperti pada wacana rubrik ALL SPORT Harian Rakyat Bengkulu tanggal 29 Maret 2018, dimana terdapat beberapa jenis penggunaan peranti kohesi.

Berdasarkan hasil pengamatan awal ditemukan beberapa peranti kohesi dan koherensi yang terdiri atas, peranti kohesi pronomina, substitusi, dan repetisi. Peranti-peranti kohesi tersebut digunakan untuk membentuk keutuhan dan kerapian wacana yang berjudul "Kerber Kesulitan Taklukkan Angin". Dengan penggunaan peranti kohesi yang tepat dan membentuk kekoherensian yang baik, maka informasi yang ingin disampaikan oleh penulis kepada pembaca tersampaikan.

Adapun pertimbangan penulis melakukan penelitian ini, yaitu ditemukan penanda kohesi dan koherensi dalam rubrik ALL SPORT seperti yang telah dijabarkan di atas. $\mathrm{Di}$ sinilah penulis ingin melihat bagaimana peranti kohesi dan koherensi yang digunakan dalam wacana rubrik $A L L$ SPORT pada Harian Rakyat Bengkulu. Judul penelitian ini adalah "Kohesi dan Koherensi Dalam Rubrik Olahraga Harian Rakyat Bengkulu.

\section{METODE}

Metode yang digunakan dalam penelitian ini adalah metode deskriptif dengan pendekatan kualitatif. Sumber data rubrik ALL SPORT pada surat kabar Harian Rakyat Bengkulu edisi Maret 2018. Data berupa teks wacana berita pada rubrik $A L L$ SPORT pada surat kabar Harian Rakyat Bengkulu edisi Maret 2018, yang berjumlah 16 teks wacana dengan rincian sebagai berikut, sepak bola 4, badminton 4, tenis 4 , pekan olahraga provinsi (porprov) 4. 
Teknik pengumpulan data yang digunakan adalah teknik dokumentasi. Dokumentasi yang diperoleh pada penelitian ini adalah berupa wacana berita yang terdapat pada rubrik ALL SPORT Harian Rakyat Bengkulu edisi Maret 2018. Analisis data yang dilakukan penulis meliputi beberapa langkah sebagai berikut: (1) membaca 16 teks wacana berita rubrik ALL SPORT Harian Rakyat Bengkulu edisi Maret 2018. (2) Pengkodean, dilakukan dengan cara memberi tanda untuk setiap wacana berita, agar memudahkan peneliti dalam menganalisis data nantinya. (3) mengidentifikasi penanda kohesi apa saja yang digunakan dalam teks wacana berita rubrik ALL SPORT pada Harian Rakyat Bengkulu edisi Maret 2018. (4) mengklasifikasi mengenai penanda kohesi dalam teks wacana berita rubrik ALL SPORT pada Harian Rakyat Bengkulu edisi Maret 2018. (5) menganalisis mengenai kekohesifan dan kekoherensian teks wacana berita rubrik ALL SPORT pada Harian Rakyat Bengkulu edisi Maret 2018. (6) membuat kesimpulan berdasarkan dari hasil analisis teks wacana berita rubrik $A L L$ SPORT pada Harian Rakyat Bengkulu edisi Maret 2018.

Keabsahan data dilakukan dengan triangulasi dalam upaya mendapatkan keabsahan data penelitian. Dilakukan dengan pengecekan menggunakan bukubuku wacana. Buku wacana yang digunakan untuk pengujian keabsahan data didasari dari teori-teori yang menunjang penelitian ini yang dilakukan oleh peneliti. Serta validasi data dilakukan oleh dosen pembimbing selama proses bimbingan berlangsung dan diskusi dengan teman sejawat dalam menganalisis penggunaan peranti kohesi dan koherensi dalam rubrik ALL SPORT pada Harian Rakyat Bengkulu.

\section{HASIL PENELITIAN DAN PEMBAHASAN Hasil}

Hasil penelitian ini menunjukkan penulis rubrik ALL SPORT pada Harian Rakyat Bengkulu edisi Maret 2018 menggunakan berbagai unsur peranti kohesi. Dari 16 wacana berita rubrik $A L L$ SPORT yang menjadi objek penelitian terdapat peranti kohesi yang bervariasi. Berikut ini penjabaran penggunaan peranti kohesi dalam wacana berita rubrik ALL SPORT pada Harian Rakyat Bengkulu, peranti kohesi yang digunakan terbagi menjadi dua yaitu peranti kohesi gramatikal dan kohesi leksikal.

Peranti kohesi gramatikal meliputi pronomina (kata ganti) yang terdiri atas (1) pronomina orang ketiga tunggal yaitu berupa kata dia, (2) pronomina orang ketiga jamak yaitu berupa kata mereka, (3) pronomina petunjuk yaitu berupa kata saat itu, (4) pronomina empunya yaitu berupa kata nya, (5) peranti kohesi substitusi yaitu berupa pergantian nama orang seperti nama Giroud digantikan dengan bomber Chelsea, sarana penunjang digantikan venue, penggantian nama menggunakan tuturan, (6) peranti konjungsi terdiri dari beberapa konjungsi pertama konjungsi adversatif yaitu namun, sedangkan, di lain sisi, konjungsi klausal sebab, lebih dari itu, untuk itu, konjungsi koordinatif dan, padahal, konjungsi subordinatif meskipun, konjungsi temporal kemudian, berikutnya, sebelumnya,(7). Selanjutnya peranti kohesi leksikal yaitu repetisi (pengulangan) seperti kata Porprov, perlombaan, turnamen dan sebagainya. berikutnya untuk kekoherensian pada wacana berita rubrik ALL SPORT Harian Rakyat Bengkulu ditandai dengan penggunaan peranti kohesi seperti pronomina, substitusi, konjungsi, dan repetisi yang tepat. Selain itu kekoherensian wacana dapat dilihat dari topik atau informasi yang terkandung di setiap paragraf, dengan cara melihat apakah di setiap paragraf menjelaskan satu 
topik dan menyampaikan informasi yang sesuai dengan judul wacana tersebut.

Peranti kohesi pronomina (kata ganti), ditemukan sebanyak 4 jenis meliputi, pronomina orang ketiga tunggal, pronomina orang ketiga jamak, pronomina penunjuk, dan pronomina empunya. Pronomina orang ketiga tunggal (dia) digunakan untuk menggantikan nama orang yang bersifat tunggal seperti pada contoh berikut, kata Kerber pada kalimat pertama digantikan dengan kata dia pada kalimat kedua.

Pronomina orang ketiga jamak digunakan untuk menggantikan nama orang yang bersifat jamak seperti pada contoh berikut nama Hendra Setiawan / Mohmamad Ahsan pada kalimat pertama digantikan dengan kata mereka pada kalimat kedua. Pronomina penunjuk digunakan untuk menunjukkan waktu seperti pada contoh berikut waktu penyelenggaraan pertandingan pada kalimat pertama digantikan dengan kata saat itu pada kalimat kedua. Dan pronomina empunya digunakan untuk menunjukkan orang dalam kedudukan sebagai pemilik seperti pada contoh berikut, nama Serena Williams kalimat pertama digantikan dengan kata adik-nya pada kalimat kedua.

Peranti kohesi substitusi (penyulihan) pada wacana berita rubrik ALL SPORT Harian Rakyat Bengkulu edisi Maret 2018. Ditemukan sebanyak 2 jenis meliputi, penggantian dengan menggunakan unsur yang lebih besar dari acuannya seperti penggantian nama Kerber menjadi Petenis Jerman. Kedua penggantian menggunakan tuturan, digunakan sebagai pengganti dari orang yang memilki tuturan tersebut. Peranti kohesi substitusi paling banyak ditemukan pada rubrik ALL SPORT. Karena wacana dalam rubrik $A L L$ SPORT berbentuk wacana berita, sehingga penulis rubrik dituntut untuk menciptakan suatu tulisan yang tidak membosankan untuk dibaca, salah satunya caranya ialah dengan menggunakan penggantian dan tidak mengulang kata yang sama.

Penambahan konjungsi ditemukan sebanyak 5 jenis meliputi, adversatif, klausal, koordinatif, subordinatif, dan konjungsi temporal. Konjungsi adversatif berupa kata namun seperti pada contoh berikut "Angka ketajaman pemain kelahiran Macon itu memang turun naik sejak roda kompetisi bergulir Agustus silam. Namun seperti halnya Cristiano Ronaldo yang ngebut catatan pundi-pundi golnya, maka Grizzi juga membaik per Januari lalu" selai itu terdapat juga konjungsi adversatif lain seperti padahal, sedangkan, di lain sisi.

Konjungsi klausal sebab seperti pada contoh berikut "Secara peringkat, Hendra/ Ahsan saat ini berada di posisi 171 dunia terpaut jauh di bawah Ellis/ Langridge yang bertengger di peringkat ke-26. Sebab, Hendra dan Ahsan sudah setahun lebih tidak bermain bersama. Otomatis point mereka di BWF (Batminton Word Federation) tidak sebanyak Ellis/ Langridge" selai itu terdapat juga konjungsi klausal lain seperti lebih dari itu, untuk itu.

Konjungsi koordinatif dan seperti pada contoh berikut "Trisula andalan Mohamed Salah, Roberto Firminio, dan Sadio Mane tetap ambil bagian. Padahal, ketiganya sudah bermain bersama dalam 10 laga terakhir. Namun, masih menurut Klopp, ketiganya membutuhkan semacam moodbooster untuk hadapi United. Dan, itu bisa didapat dengan tetap mempercayai mereka jadi starter melawan Porto".

Konjungsi subordinatif meskipun seperti pada contoh berikut "Khusus ganda putra, Herry Iman Pierngadi melihat tiga pasangan tersebut masih solid. (2)“kecuali ada cedera, mereka masih jadi prioritas kami," urainya. Meskipun demikian, para pemain pelapis seperti Fajar Alfian /M.Rian Ardianto, Berry Angriawan/ Hardianto, dan Ade Yusuf/Wahyu Nayaka bisa menjadi opsi lainnya". 
Konjungsi temporal sebelumnya seperti pada contoh berikut "Sementara itu, Hendri Saputra, pelatih tunggal putra platnas menjelaskan sejauh ini konfidensi pemain muda di platnas sudah cukup teruji. ${ }^{(2)}$ Meskipun demikian, terkait peluang Tommy, dia pun tidak menutup kemungkinan yang ada. Sebelumnya, tim tunggal putra Indonesia bermaterikan Jhonatan Christie, Ihsan Maulana Mustofa, Anthony SinisukaGinting dan Firman Abdul Kholik" selain itu terdapat juga konjungsi temporal lain seperti kemudian, berikutnya.

Kohesi leksikal berupa repetisi (pengulangan) seperti pada contoh berikut "Dengan dukungan langsung sang suami Alexis Ohanian yang hadir di lapangan, Williams butuh waktu 1 jam 30 menit untuk mengakhiri perlawanan dari Diyas. ${ }^{(2)}$ Ini kali pertama Williams tampil di ajang resmi sejak final Australia Terbuka 2017 pada Januari tahun lalu" nama Williams pada kalimat kedua merupakan pengulangan unsur yang sama pada kalimat pertama. pengulangan itu dilakukan untuk menunjukkan bahwa Williams merupakan pokok pembahasan dalam paragraf tersebut.

Kekoherensian pada wacana berita rubrik ALL PORT Harian Rakyat Bengkulu edisi Maret 2018 ditunjukkan dengan penggunaan peranti kohesi gramatikal seperti pronomina, substitusi, konjungsi, dan leksikal berupa kohesi repetisi yang tepat. Selain itu kekoherensian wacana juga ditunjukkan dari topik atau informasi yang terkandung di setiap bagian wacana dengan cara melihat apakah di setiap bagian wacana menjelaskan satu topik dan menyampaikan informasi yang sesuai dengan judul wacana. Seperti pada contoh "Hasil ini sekaligus memupus harapan Kerber meraih titel keduanya sepanjang 2018. Januari lalu dia mengawali musim dengan apik saat menjadi kampiun di Sydney Internasional. Untung rekornya sampai saat ini masih lumayan apik. Kini dia punya rekor 21-5 dari enam kejuaraan" Pada contoh tersebut terdapat beberapa peranti kohesi meliputi pronomina orang ketiga tunggal (dia) pada kalimat pertama dan keempat, kohesi empunya berupa kata (rekornya) yang terdapat pada kalimat ketiga. Kohesi pronomina orang ketiga tunggal dan pronomina empunya memiliki hubungan satu sama lain, karena samasama mengacu kepada nama Kerber pada paragraf pertama, sehingga setiap kalimat memiliki keutuhan bentuk dan memiliki hubungan makna, selain itu dengan adanya peranti kohesi tersebut membuat setiap kalimat memperkuat satu topik yang sama, sehingga terbentuk kekoherensian. Dengan demikian penggunaan peranti kohesi gramatikal dan kohesi leksikal yang tepat membentuk kekohesrensian dalam wacana berita rubrik ALL PORT Harian Rakyat Bengkulu edisi Maret 2018.

\section{Pembahasan}

Berdasarkan hasil penelitian telah diidentifikasi yaitu sebanyak 4 jenis peranti kohesi yang terdiri dari pronomina. Pronomina terbagi menjadi empat yaitu, pronomina orang ketiga tunggal berupa dia, pronomina orang ketiga jamak berupa mereka, pronomina penunjuk berupa saat itu, pronomina empunya berupa nya. Kedua peranti kohesi substitusi berupa penggantian nama seperti nama Giroud digantikan dengan bomber Chelsea, penggantian nama dengan menggunakan tuturan dan penggantian dengan kata begitu. Ketiga konjungsi, konjungsi terdiri dari konjungsi adversatif yaitu namun, sedangkan, di lain sisi, konjungsi kausal sebab, lebih dari itu, untuk itu, konjungsi koordinatif dan, padahal, konjungsi subordinatif meskipun, konjungsi temporal sebelumnya, kemudian, berikutnya, sebelumnya. Keempat peranti kohesi leksikal repetisi (pengulangan) seperti kata Porprov, perlombaan, turnamen. Dengan adanya penggunaan peranti kohesi 
tersebut, maka terbentuklah kekohesifan pada rubrik ALL SPORT Harian Rakyat Bengkulu edisi Maret 2018.

Kekoherensian pada wacana berita rubrik ALL PORT Harian Rakyat Bengkulu edisi Maret 2018 ditunjukkan dengan penggunaan peranti kohesi gramatikal seperti pronomina, substitusi, konjungsi, dan leksikal berupa kohesi repetisi. Hal tersebut sejalan dengan penelitian sebelumnya bahwa setiap kekoherensian wacana dapat ditandai oleh peranti kohesi. Selain itu kekoherensian wacana juga ditunjukkan dari topik atau informasi yang terkandung di setiap paragraf dengan cara melihat apakah di setiap paragraf menjelaskan satu topik serta menyampaikan informasi yang sesuai dengan judul wacana tersebut. Dengan demikian penggunaan peranti kohesi gramatikal dan kohesi leksikal yang tepat membentuk kekoherensian dalam wacana.

Pada penelitian ini peranti kohesi substitusi lebih banyak digunakan dari pada peranti lainnya, hal itu dikarenakan wacana rubrik ALL SPORT merupakan wacana berita. Dengan begitu penggunaan peranti kohesi substitusi digunakan penulis rubrik ALL SPORT sebagai alat pembentuk tulisan yang tidak membosankan untuk dibaca dan dapat memberikan informasi yang lebih kepada pembaca. Selain itu penggunaan peranti kohesi substitusi tersebut membuat kalimat tidak berulang-ulang sehingga informasi yang ingin disampaikan penulis tersampaikan kepada pembaca. Sehingga peranti kohesi substitusi memiliki peran yang penting dalam pembentukan keutuhan dalam wacana berita rubrik $A L L$ SPORT Harian Rakyat Bengkulu

Berdasarkan penjelasan di atas dapat dikatakan bahwa penelitian ini melanjutkan dari penelitian sebelumnya. karena penelitian ini juga menganalisis tentang penggunaan peranti kohesi dan koherensi, namun yang membedakan penelitian ini dengan penelitian sebelumnya, yaitu objek penelitian serta ditemukan peranti kohesi yang berupa peranti kohesi substitusi, karena pada penelitian ini ditemukan peranti substitusi berupa penggantian nama seseorang dengan unsur yang lebih besar yang bertujuan untuk menambah informasi bagi pembaca, serta penggantian dengan menggunakan tuturan dari orang yang di acuhnya. Sedangkan penelitian sebelumnya hanya menemukan peranti kohesi substitusi berupa kata begitu, itu, seperti itu, dan sama. selain itu.

\section{PENUTUP \\ Kesimpulan}

Berdasarkan hasil penelitian yang telah dilakukan pada wacana berita rubrik ALL PORT Harian Rakyat Bengkulu edisi Maret 2018, dapat disimpulkan bahwa rubrik ALL SPORT Harian Rakyat Bengkulu menggunakan peranti kohesi gramatikal dan kohesi leksikal yang tepat sehingga setiap paragraf mengandung informasi yang sesuai dengan judul wacana, serta memperkuat satu topik yang sama. Dengan demikian terbentuklah kekohesifan dan kekoherensian pada wacana berita rubrik ALL SPORT Harian Rakyat Bengkulu. Kohesi gramatikal tersebut meliputi, pronomina, substitusi, dan konjungsi. Pronomina meliputi pronomina orang ketiga tunggal (dia), pronomina orang ketiga jamak (mereka), pronomina penunjuk (saat itu), pronomina empunya (nya). Penggunaan peranti substitusi meliputi penggantian dengan unsur yang lebih besar dari acuannya dan penggantian dengan menggunakan tuturan, peranti kohesi substitusi lebih banyak digunakan dari pada peranti lainnya sehingga peranti kohesi memiliki peram khusus. Penggunaan konjungsi meliputi konjungsi adversatif, klausal, koordinatif, subordinatif, serta konjungsi temporal. 
Saran

Berdasarkan kesimpulan yang telah disampaikan di atas, peneliti menyampaikan saran sebagai berikut:

1. Penelitian tentang penggunaan peranti kohesi dan koherensi pada wacana berita rubrik ALL PORT Harian Rakyat Bengkulu edisi Maret 2018 masih terbatas, karena pada penelitian ini hanya melihat penanda apa saja yang digunakan bukan melihat kesalahan penggunaannya. Oleh sebab itu, untuk peneliti selanjutnya perlu dilakukan analisis yang lebih lanjut dengan melihat kesalahan serta ketepatan peranti kohesi yang digunakan, agar mendapat hasil yang lebih lengkap.

2. Penelitian ini objeknya masih terbatas pada rubrik ALL SPORT Harian Rakyat Bengkulu edisi Maret 2018. Oleh karena itu untuk penelitian selanjutnya lebih baik objek penelitian ditambah dengan rubrik lain pada Harian Rakyat Bengkulu seperti rubrik kriminal, rubrik ekonomi, maupun tajuk rencana sebagai objek penelitian, agar peranti kohesi dan koherensi yang ditemukan lebih bervariasi.

\section{DAFTAR PUSTAKA}

Badara, Aris. 2012. Analisis Wacana. Jakarta: Kencana Prenada Media.

Kridalaksana, Harimurti. 1983. Kamus Linguistik. Jakarta: Gramedia Pustaka Utama.

Sukino. 2004. Memahami Wacana Bahasa Indonesia: Bengkulu: Perpustakaan Unib.

Tarigan, H. G. 2009. Pengajaran Wacana. Bandung: Angkasa.

Tim Penyusun Kamus Pusat Bahasa. 2001. Kamus Besar Bahasa Indonesia. Jakarta: Balai Pustaka. 